\title{
Alternative approach to treating malignant glaucoma after trabeculectomy with unplanned zonulectomy
}

This article was published in the following Dove Press journal:

Clinical Ophthalmology

24 April 2010

Number of times this article has been viewed

\author{
Naoki Ozeki' \\ Kenya Yuki' \\ Itaru Kimura ${ }^{1,2}$ \\ 'Department of Ophthalmology, Keio \\ University School of Medicine, Tokyo, \\ Japan, ${ }^{2}$ Department of Ophthalmology, \\ Juntendo University Urayasu Hospital, \\ Chiba, Japan
}

Purpose: To report the role of Healon $5^{\mathrm{TM}}$ injection combined with medications in patient with malignant glaucoma after trabeculectomy with unplanned zonulectomy.

Methods: Two days after trabeculectomy with unplanned zonulectomy for neovascular glaucoma in an eye with diabetic retinopathy, a patient developed malignant glaucoma due to the ciliovitreal block caused by the vitreous herniation through the peripheral iridectomy to the limbal incision with flat bleb and anterior chamber, and the intraocular pressure was elevated to $33 \mathrm{mmHg}$. The medications for the management of malignant glaucoma failed to relieve the malignant mechanism, and Healon $5^{\mathrm{TM}}$, a viscoadaptive, viscoelastic, and ophthalmic viscosurgical device, was injected through a paracentesis until the anterior chamber became deep enough to block the vitreous herniation to the limbal incision.

Results: After Healon5 ${ }^{\mathrm{TM}}$ injection, the intraocular pressure was reduced enough that the bleb was re-formed, and the anterior chamber remained deep, even without medication.

Conclusions: In patients presenting with malignant glaucoma after trabeculectomy with unplanned zonulectomy, Healon $5^{\mathrm{TM}}$ injection, combined with medications, may be a safe and effective approach before performing vitrectomy.

Keywords: malignant glaucoma, unplanned zonulectomy, ophthalmic viscosurgical device, corneal endothelial cell

\section{Case report}

A 55-year-old Japanese man was referred to the Keio University Hospital with pain in the right eye. He had been diagnosed with diabetes mellitus eight years earlier. His best-corrected visual acuity (BCVA) was 4/200 in the right eye and 4/4 in the left eye. The intraocular pressures (IOPs) were $51 \mathrm{mmHg}$ in the right eye and $18 \mathrm{mmHg}$ in the left eye. Ophthalmological examination showed iris rubeosis and proliferative diabetic retinopathy without vitreous hemorrhage in his right eye. The angle of the right eye was difficult to examine because of a shagreen patch on the cornea. The angle of the left anterior chamber was open (Shaffer 4) but profuse neovascularization was found in the entire angle. Panretinal photocoagulation was performed on both eyes, and the right eye was medically treated with topical $0.5 \%$ timolol maleate, $1 \%$ brinzolamide, $0.005 \%$ latanoprost, oral acetazolamide, and intravenous mannitol. However, this regimen failed to control the IOP adequately, and trabeculectomy with mitomycin $\mathrm{C}$ was performed.

At the end of the operation, a bleb did not form when balanced salt solution was injected into the anterior chamber, and the digitally-measured IOP appeared to be high. The conjunctiva and scleral flap were opened again, and herniated vitreous was
Correspondence: Itaru Kimura Department of Ophthalmology, Keio University School of Medicine,

35 Shinano-machi, Shinjuku-ku,

Tokyo, 160-8582, Japan

Tel $+8 \mid 33353$ I III ext 62402

Fax +81333598302

Email kimura@sc.itc.keio.ac.jp 
found in the bleb. An unplanned zonulectomy appeared to have been performed during the peripheral iridectomy. After removal of as much vitreous as possible by forceps, the bleb was reconstructed and the IOP felt normal when determined digitally.

Two days after the operation, the bleb and anterior chamber were flat, and the IOP was $33 \mathrm{mmHg}$ (Figure 1). Because a ciliovitreal block, caused by a recurrence of the vitreous herniation through the peripheral iridectomy to the limbal incision, was suspected, and no signs of choroidal effusion were detected, a diagnosis of malignant glaucoma was made.

Topical atropine, beta-blocker, oral acetazolamide, and intravenous mannitol did not relieve the malignant glaucoma, and the IOP remained over $20 \mathrm{mmHg}$ for 3 days. On the 5th postoperative day, Healon5 ${ }^{\mathrm{TM}}$ (Abbott Medical Optics, Santa Ana, CA), a viscoadaptive, viscoelastic, and an ophthalmic viscosurgical device, was injected through a paracentesis into the anterior chamber. However, the Healon $5^{\mathrm{TM}}$ did not block the aqueous humor route to the area of the trabeculectomy. The same medications were continued.

On the next day, the IOP was reduced to $14 \mathrm{mmHg}$, the bleb was reconstructed, and the anterior chamber remained deep (Figure 2). All the antiglaucoma medications were discontinued at this time. On the 18th postoperative day, phacoemulsification and intraocular lens implantation was performed on the right eye, because the cataract had progressed, due to a lens touch with the iridocornea during the malignant glaucoma attack. The BCVA improved to $4 / 10$ in the right eye after the cataract surgery. The patient's last visit was 4 months after the Healon $5^{\mathrm{TM}}$ injection. The anterior chamber remained deep and the bleb continued to function. The IOP was well controlled at 8 to $14 \mathrm{mmHg}$ without antiglaucoma medications.

\section{Discussion}

In our case, because a herniation of vitreous into the filtration area was suspected as the cause of the malignant glaucoma, we injected Healon $5^{\mathrm{TM}}$ into the anterior chamber, in order to create a deep anterior chamber, and to block the vitreous herniation. This approach was successful, and the malignant mechanism did not recur in the period of almost two weeks, until a more rigid and deep anterior chamber was constructed by cataract surgery.

Brown et al reported Nd YAG hyaloidotomy through the surgical iridotomy site in phakic malignant glaucoma, ${ }^{1}$ but this method is thought to have its limitations.

Our approach is simple and safe; it may be effective for patients with findings similar to our case, and would be an

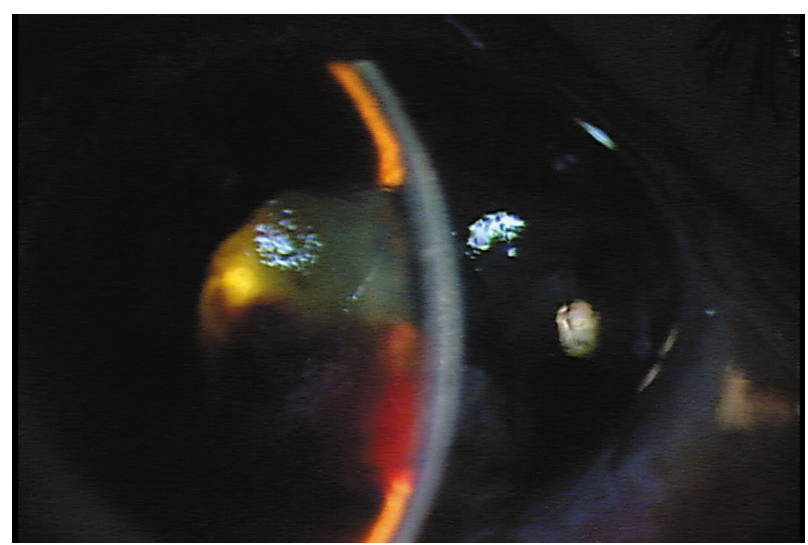

Figure I Flat anterior chamber two days after trabeculectomy. The bleb and anterior chamber are flat and the intraocular pressure was elevated to $33 \mathrm{mmHg}$.

option to consider before performing vitrectomy. Hoffman et al reported a case of flat anterior chamber due to overfiltration and hypotony after trabeculectomy, in which the injection of Healon $5^{\mathrm{TM}}$ deepened the anterior chamber. ${ }^{2} \mathrm{We}$ suggest that Healon $5^{\mathrm{TM}}$ injection combined with antiglaucoma medications may be effective even in treating malignant glaucoma similar to our case, for a flat anterior chamber.

In watertight surgery such as cataract surgery, sodium hyaluronate interferes with the aqueous outflow, and the IOP rises. ${ }^{3,4}$ However, there is still filtering after trabeculectomy, and low viscosity sodium hyaluronate, such as Healon $5^{\mathrm{TM}}$, flows out through the filtration area and does not maintain the depth of the anterior chamber. Dick et al reported that the mean viscosity at zero shear rate was 243 Pas for Healon $5^{\mathrm{TM}}$, and 5525 Pas for Healon $5^{\mathrm{TM}} .5$ The superviscous properties of Healon $5^{\mathrm{TM}}$ under low turbulence conditions may be helpful in maintaining the anterior chamber depth, to preserve aqueous outflow through the filtration area.

The loss of corneal endothelial cell after trabeculectomy is caused by a flat and shallow anterior chamber in most

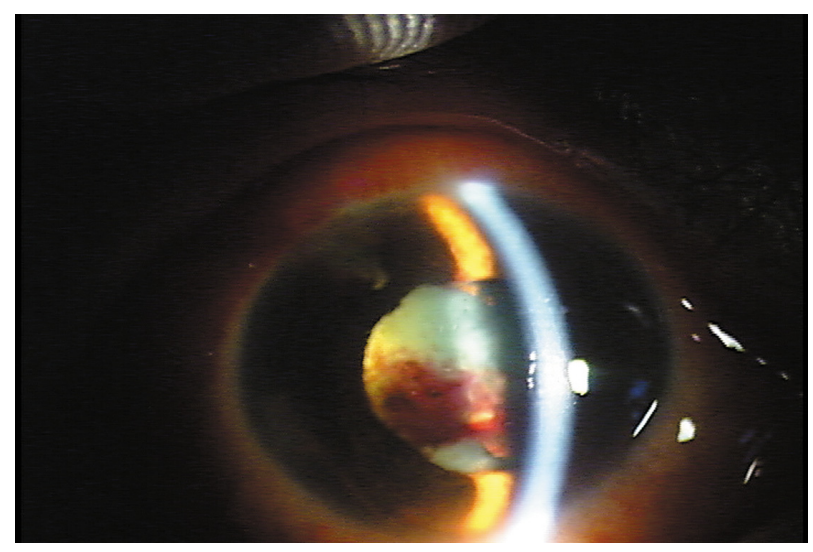

Figure 2 Deepened anterior chamber on the day after Healon $5^{\mathrm{TM}}$ injection. The bleb and anterior chamber are deepened and the intraocular pressure has decreased to $14 \mathrm{mmHg}$. 
cases. ${ }^{6}$ Therefore, deepening the anterior chamber by an injection of Healon $5^{\mathrm{TM}}$ in eyes similar to our case is also helpful for protecting corneal endothelial cell, and is an option to be considered.

\section{Acknowledgment/disclosures}

The authors report no conflicts of interest in this work. We appreciate the late Dr Yuichiro Ohtake for his clinical advice.

\section{References}

1. Brown RH, Lynch MG, Tearse JE, Nunn RD. Neodymium-YAG vitreous surgery for phakic and pseudophakic malignant glaucoma. Arch Ophthalmol. 1986;104(10):1464-1466.
2. Hoffman RS, Fine IH, Packer M. Stabilization of flat anterior chamber after trabeculectomy with Healon5. J Cataract Refract Surg. 2002;28(4):712-714.

3. Jurqens I, Matheu A, Castilla M. Ocular hypertension after cataract surgery: a comparison of three surgical techniques and two viscoelastics. Ophthalmic Surg Lasers. 1997;28(1):30-36.

4. Tanaka T, Inoue H, Kudo S, Ogawa T. Relationship between postoperative intraocular pressure elevation and residual sodium hyaluronate following phacoemulsification and aspiration. $J$ Cataract Refract Surg. 1997;23(2):284-288.

5. Dick HB, Krummenauer F, Augustin AJ, Pakula T, Pfeiffer N. Healon5 viscoadaptive formulation: Comparison to Healon and Healon GV. J Cataract Refract Surg. 2001;27(2):320-326.

6. Fiore PM, Richter CU, Arzeno G, et al. The effect of anterior chamber depth on endothelial cell count after filtration surgery. Arch Ophthalmol. 1989;107(11):1609-1611.
Clinical Ophthalmology

\section{Publish your work in this journal}

Clinical Ophthalmology is an international, peer-reviewed journal covering all subspecialties within ophthalmology. Key topics include: Optometry; Visual science; Pharmacology and drug therapy in eye diseases; Basic Sciences; Primary and Secondary eye care; Patient Safety and Quality of Care Improvements. This journal is indexed on

Submit your manuscript here: http://www.dovepress.com/clinical-ophthalmology-journal

\section{Dovepress}

PubMed Central and CAS, and is the official journal of The Society of Clinical Ophthalmology (SCO). The manuscript management system is completely online and includes a very quick and fair peer-review system, which is all easy to use. Visit http://www.dovepress.com/ testimonials.php to read real quotes from published authors. 